\title{
DYNAMIC MICRO-TESTING OVER A LARGE RANGE OF STRAIN RATES FOR HOMOGENOUS AND HETEROGENEOUS LOCAL MATERIAL CHARACTERIZATION
}

\author{
FRANK HUBERTH, JOERG LIENHARD, BALAJI RAGUPATHI \& MAX HAUBER \\ Fraunhofer-Institute for Mechanics of Materials IWM, Germany
}

\begin{abstract}
The dynamic material characterization shows different macroscopic strain rate effects. The causal mechanisms cannot be identified at this level in most cases. Micro-tests allow a local transient analysis, which is illustrated in this article using the example of a long-fibre reinforced thermoplastic (LFRT). After a general introduction, the development and validation of a micro-test for a large strain rate range is presented. The validation explained for steel shows the advantage of the small sample for the dynamic characterization, if a homogenous material behaviour of this magnitude still exists, especially in the case of low-vibration force measurement. For a heterogeneous LFRT material, the micro-test shows strongly scattering test results that are no longer representative of the homogenized mechanical material behaviour, but reflect the local characteristics. These local properties are directly caused by the injection moulding process. Further SEM analyses of the samples indicate different macromolecular deformation mechanisms of the matrix at the different strain rates.
\end{abstract}

Keywords: material characterization, strain rate effect, micro-testing, crash, impact.

\section{INTRODUCTION}

The loading speed can influence the mechanical behaviour of a material. The influence of the load speed is usually described by the strain rate $\mathrm{d} \varepsilon / \mathrm{dt}$ as the time derivative of the strain resulting from the load. In the standard tensile test for metallic materials according to DIN EN ISO 6892-1 [1] quasi static loads are applied to the sample at very low load speeds (from strain rates $\left.\mathrm{d} \varepsilon / \mathrm{dt}=0.00007 \mathrm{~s}^{-1}\right)$. In many load cases, in particular at crash and impact, significantly higher strain rates are achieved in the components. The experimental procedure for the dynamic tensile test was presented in a FAT guideline "Dynamic Material Characteristics for Crash Simulation" (AiF No. 14205) [2] and based thereon was implemented in a standard "BS ISO 26203-2 Metallic materials Tensile testing method at high strain rates Part 2: Servo-hydraulic and other test systems" [3].

For these applications, first and foremost fast servo hydraulic test systems are used. For higher loading rates and resulting strain rates, other experimental equipment has to be used then, like e.g. gas pressure accelerators or so-called bar systems, such as the Split Hopkinson Bar. The various test facilities allow partially overlapping areas of loading speeds with different challenges and restrictions. During the dynamic test for crash and impact, in particular the force measurement is an essential issue. For this purpose, a patented force measurement (DE10201861) was developed at the Fraunhofer IWM for the middle strain rate range.

Another way is not to increase the strain rate, but to adjust the sample geometry to achieve higher strain rates. The strain rate range for the discussed experiments ranges from $10^{-3} \mathrm{~s}^{-1}$ to more than $1000 \mathrm{~s}^{-1}$. 


\section{MICRO-TEST CONCEPT, METROLOGY AND VALIDATION}

In order to realize material characterization over a large strain rate range on a single testing facility, two approaches, variable loading speed up to several meter per second and reduced sample design were realized for a new experimental setup. The extreme reduction of the sample size is motivated not only by the thus achievable strain rates, but also by locally focused observation and measurement in small scale ranges for local material characterization. The requirements were implemented in the testing facility IWM DynMicro [4], [5].

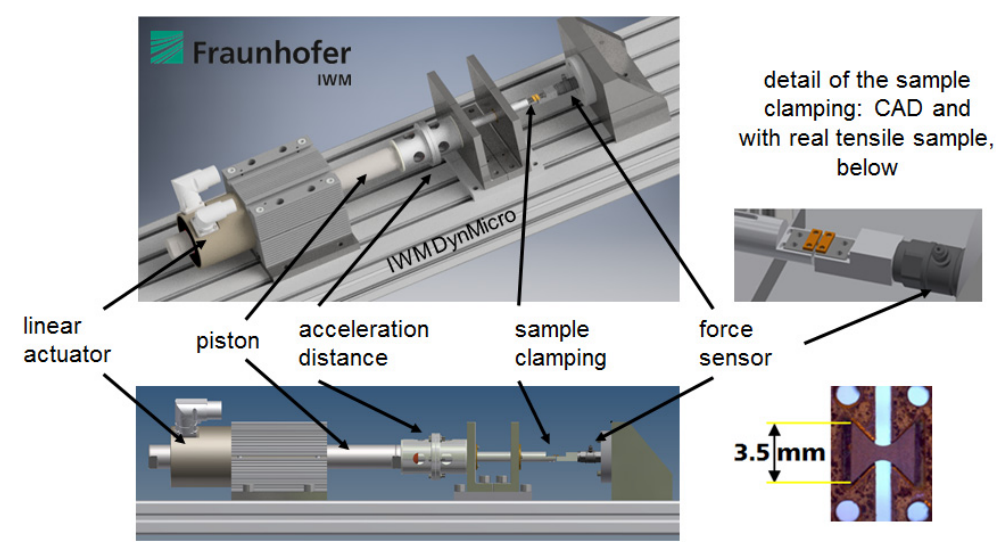

Figure 1: Test facility IWM DynMicro (CAD representation) for tests on small samples over a large strain rate range [5].

The IWM DynMicro has been tested on dual phase steel DP 500 (HCT 490X) and verified with macroscopic investigations on approved IWM mini tensile specimens with $14 \mathrm{~mm}$ gauge length at comparable nominal strain rates. The micro samples had a test area of $1.5 \times 0.8 \mathrm{~mm}$ with an original sheet thickness of $0.5 \mathrm{~mm}$. The strain rate range considered in the micro-tests included nominal strain rates of $0.001 \mathrm{~s}^{-1}$ to $1000 \mathrm{~s}^{-1}$. The strains were determined optically on the sample in both test series for a defined measuring length with the aid of digital image correlation, DIC (gom ARAMIS). Local strain rates were even higher than $1000 \mathrm{~s}^{-1}$.

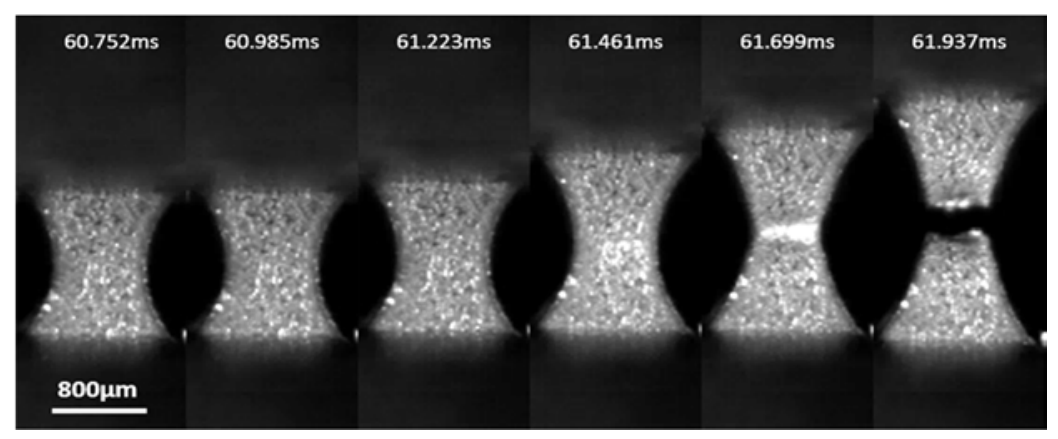

Figure 2: High speed video series micro tensile test steel at $1 \mathrm{~ms}^{-1}$ load speed, 300,000 frames per second (fps) [4]. 

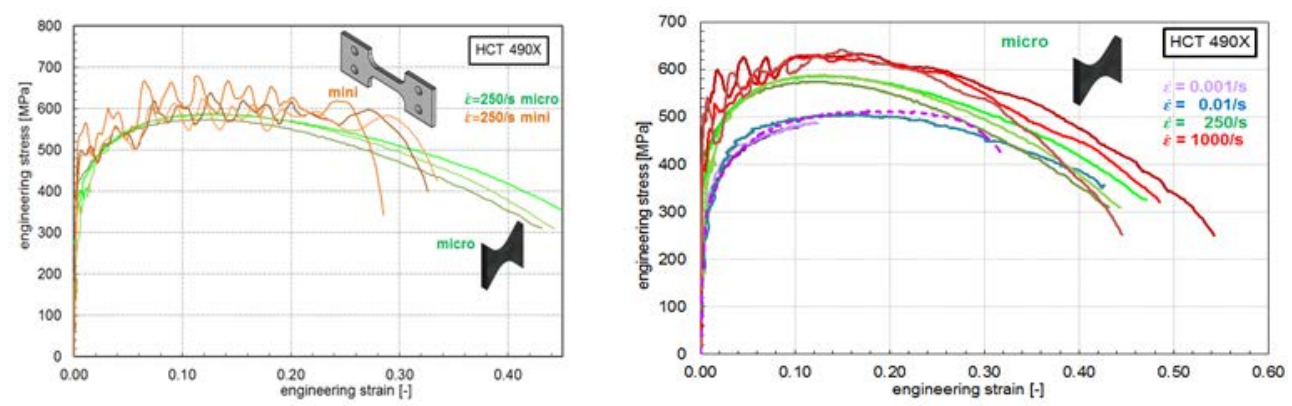

Figure 3: Technical stress-strain diagrams of the mini and micro samples for strain rates $250 \mathrm{~s}^{-1}$ in comparison (left) and the overview of the micro experiments for the different strain rates with a supplemented dashed curve for a quasi-static microtest (right) [6].

Since the chosen material shows a very fine microstructure, it was possible to reproduce the material behaviour in the micro-tests with a measuring length of $1 \mathrm{~mm}$ as well as the tensile tests with a larger sample and a measuring length of $14 \mathrm{~mm}$.

The measurement shows in the micro tensile test with a nominal elongation rate of $250 \mathrm{~s}^{-1}$ significantly lower vibrations in the dynamic force measurement, even in comparison with the patented IWM load cell measurement.

The experiments with $1000 \mathrm{~s}^{-1}$ provide usable results without additional optimization of the force measurement. Tests at higher rates showed significant oscillations in the force measurement. Adapting the quasi local force measurement is actually under development.

The verification test series showed the reliability and the benefit of the micro tensile tests and the main influencing factors like the sample preparation, the clamping system and the sensitivity to misalignment which are to be considered. An essential point for the successful introduction of the rate dependent tests was the application of the high speed camera system for the DIC at the micro scale for the deformation analysis on the sample. For such small samples the results are influence significantly by every setting or additional elasticities in the measuring length.

\section{LOCAL STRAIN RATE EFFECTS ON DEFORMATION AND FAILURE FOR LFRT AND RESULTING GLOBAL MATERIAL RESPONSE}

The influence of the strain rate for thermoplastics, reinforced thermoplastic materials and other composites was investigated by conventional large samples. The observation of the strain rate effect changed significantly from the pure thermoplastic matrix material and for the composites. The following diagrams directly show the difference for the pure matrix material (PP), the same thermoplastic matrix with long glass fibre reinforcement (LFRT) and a carbon fibre composite (CFRP).

For the pure PP matrix stress increases with increasing strain rate and failure strain decreases. For the other two materials a revers strain rate effect was observed for the failure strain. This effect was measured as shown in the diagrams and transferred into phenomenological material models for FEM simulations [7], [8] but the fundamental material behaviour of the responsible fibre matrix interaction is not assessable by these tests and neglected in homogenous phenomenological material models. For this purpose local material investigations were performed. 

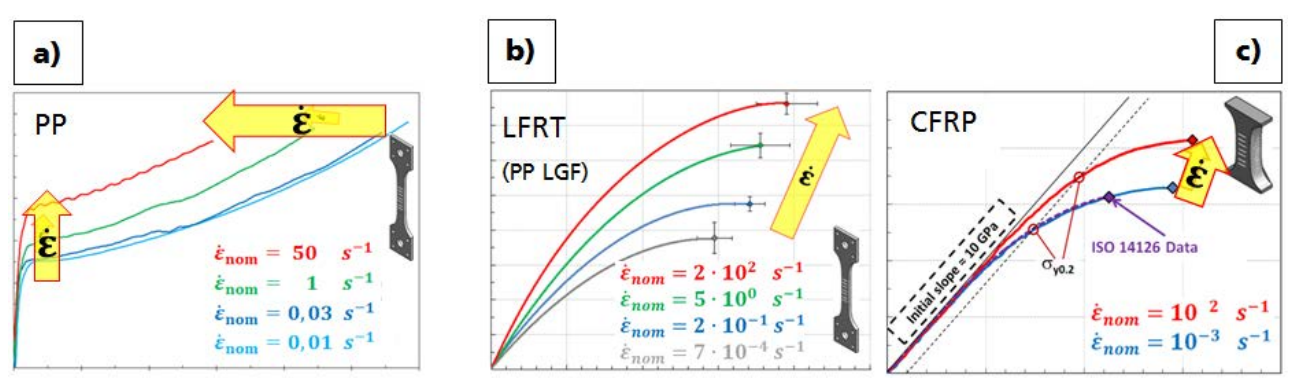

Figure 4: Tensile strain rate effect on the stress level and the failure strain for (a) thermoplastic (PP matrix) material; (b) long glass fibre reinforced PP (PP-LGF) [7], [8]; and (c) a unidirectional carbon fibre laminate [9].

Micro tensile tests allow not only high strain rates but also the transient investigation of the local heterogeneous material behaviour, depending on the microstructure. This is demonstrated using the example of a long glass fibre reinforced material (LFRT) with PP matrix (PP-LGF) [10]. This LFRT is used in many areas, especially in the automotive, which are exposed to high loads and load. These investigations of micromechanics of fibres and matrix at different strain rates were part of a research project. Here, the local fibre-matrix behaviour, in particular the orientation of the fibres and the damage of fibres and matrix were considered.

The samples were taken at different positions and variably over the wall thickness and prepared to observe the then partially visible fibres can. The local structure for each sample was influenced by the injection moulding process. For this reason, the tests show a large scatter, but represent the locale material behaviour as given in the component.

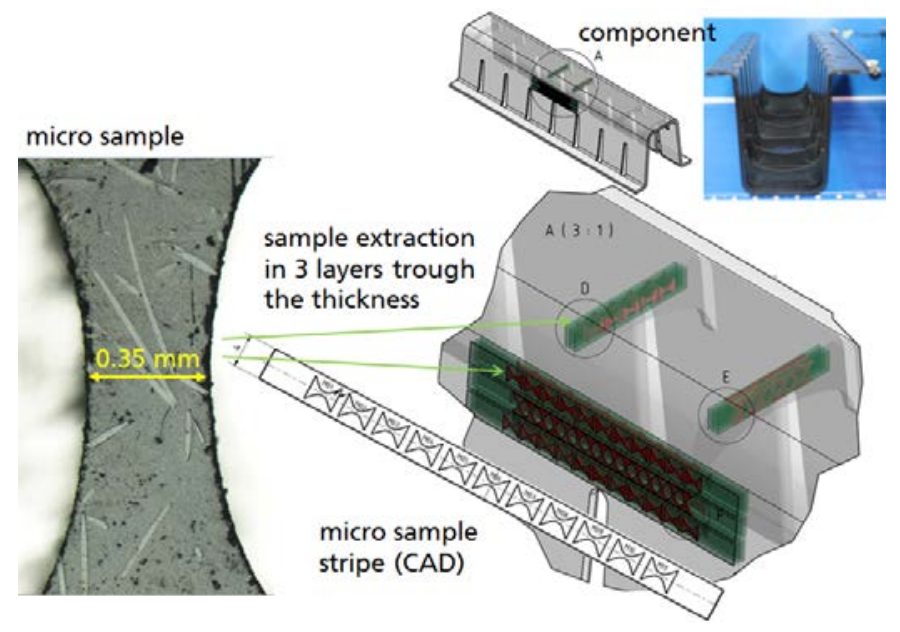

Figure 5: Sample extraction of injection moulded LFRT components (top right) in three layers as stripes (centre), polished and then cut as micro tensile samples (left) [10]. 
The sample extraction was done by a special micro water jet cutting technology and a finishing process. In the first step segments were prepared from components. These were used for preparing thin strips of $0.5 \mathrm{~mm}$ thickness in different position of the wall thickness of the segments. The sample geometry was cut in the stripes after a polishing process. By this special adapted process a very good bonding of surface fibres was achieved.

Micro-tests depend on a customized sample preparation, adapted for each material. This is essential for the tests.

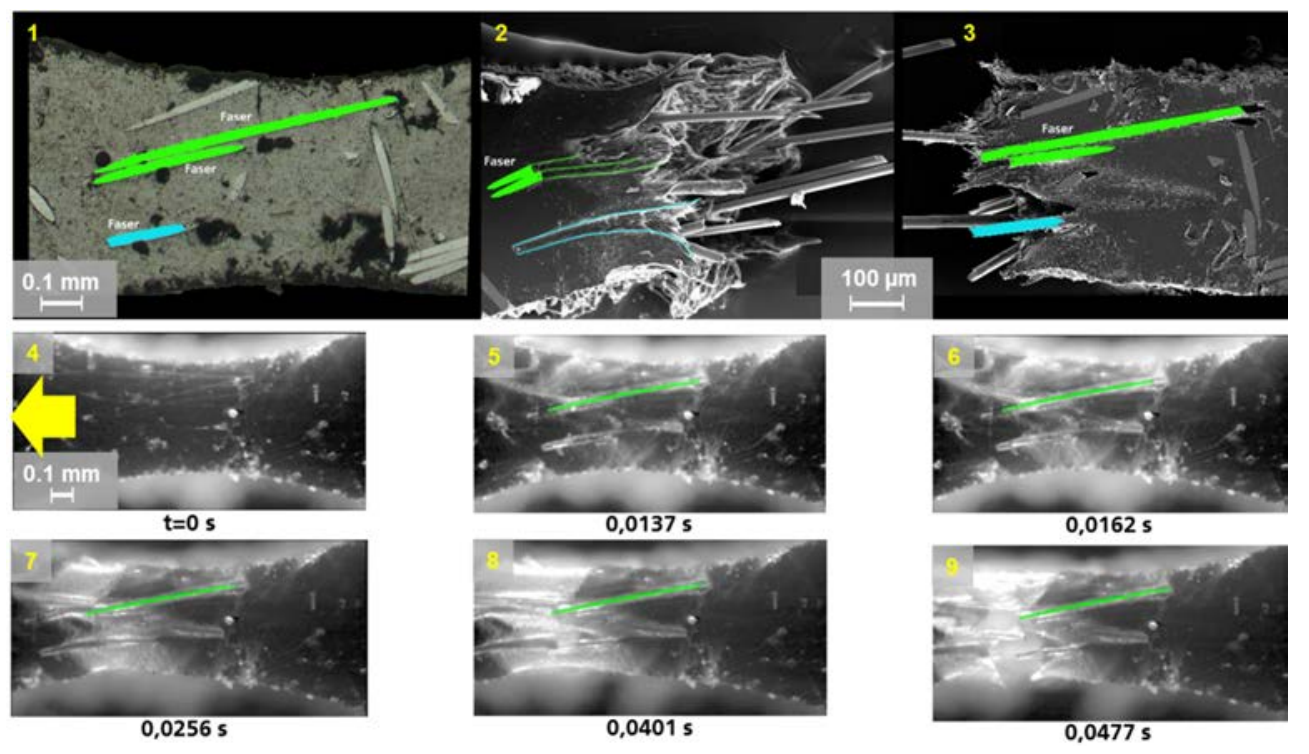

Figure 6: Micro tensile test PP-LGF; Micrograph polished sample (1), SEM images of the fractured ends (2) and (3); and high-speed image series (4 to 9 at 10,000 fps) of the experiment. The deformation zone at quasi-static loading is more localized around the fibres compared to the dynamic load. The local deformations indicate highly stretched polymer matrix at low strain rate and increased craze formation at higher strain rates.
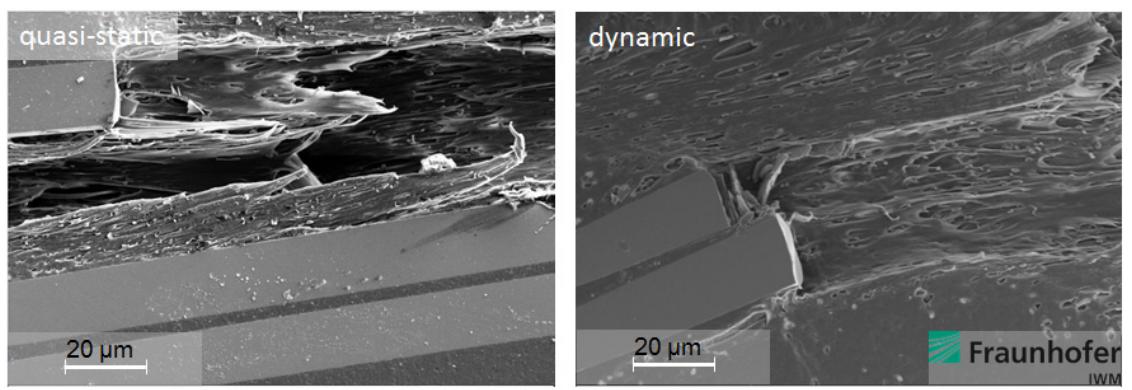

Figure 7: SEM micrograph PP LGF after quasi-static loading, left and dynamic loading, right, with fiber break and fiber pullout rates [10]. 
The results show different fibre-matrix interaction depending on the strain rate. This could be proven by the SEM examinations of the tested micro samples. The advantage here is to map the entire micro specimen and then zoom locally into the damage area. The SEM images clearly show local differences in the fibre environment with respect to the local deformations and their propagation around the fibres for different strain rates. This observation is an essential step of understanding the local strain rate effect, influencing the macroscopic LFRT reaction on different strain rates.

\section{APPLICATION OF MICRO-TESTING FOR LOCAL BONDING STRENGTH CHARACTERIZATION}

These applications of the micro tensile test are further developed and optimized at Fraunhofer IWM. The possibilities are expanded for other material groups and material composites, in particular joining zones. MPW is a joining process that allows the combination of heterogeneous material combination like steel and aluminium what is essential for mixed lightweight constructions [11].

As shown for the LFRT the samples for the joint characterization were extracted in stripes and then the shape of the micro tensile samples was cut in the stripes. Here a combined process of spark erosion and micro waterjet cutting was applied.

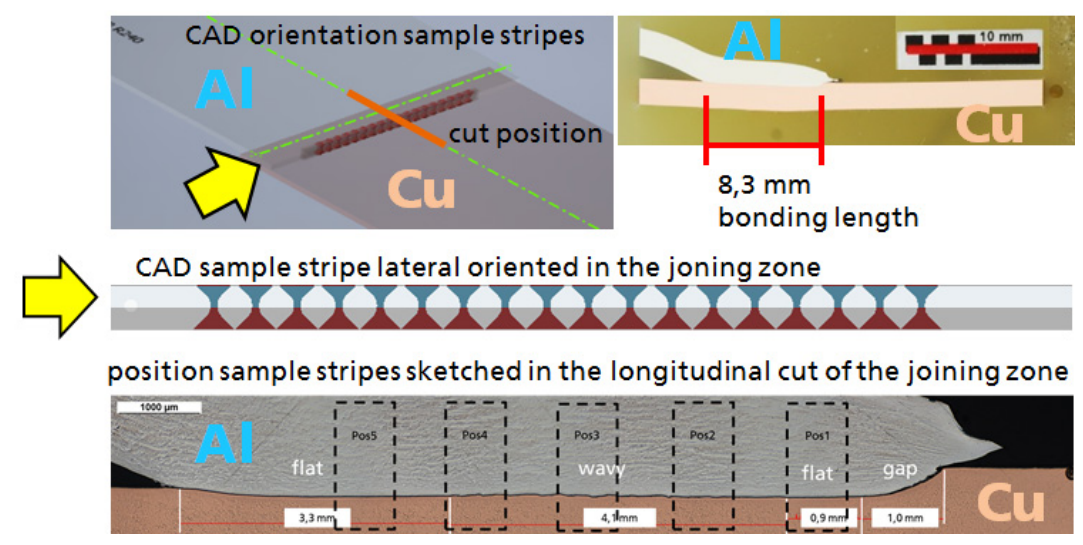

Figure 8: Micro tensile samples prepared out of a MPW joint of copper and aluminum, CAD sketch of the location in the coupon samples prepared in stripes, metallographic cut of the coupon sample overview and zoomed in with marked positions of the stripe extraction.

The analysis of this local joint is actually in progress by micro tensile tests. First results for a copper-aluminium combination are shown in the following image series. As shown in the series of images in Fig. 9, the MPW joint is stronger than the aluminium material. In a next step the sample shape will be adapted to strengthen the aluminium part and to force failure in the copper and the very small welding line pictured for two different samples in Fig. 10. This testing procedure allows the local determination of all strength values for the simulation.

This characterization concept can be transferred to other joints, like adhesives. The shape of the sample will be adapted to the geometries of the joined components and the bonding layer. 

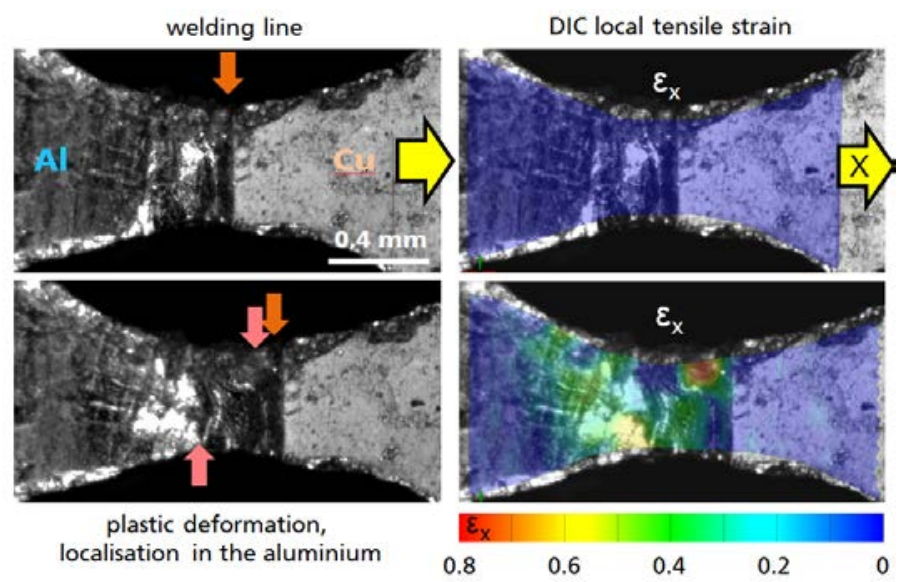

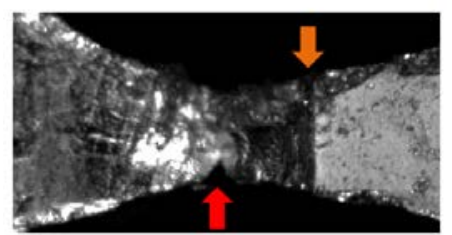

failure in the aluminium

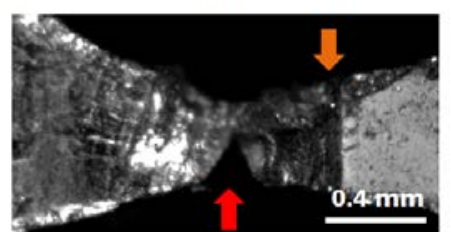

failure in the aluminium

Figure 9: Micro tensile test for a MPW joint of aluminum (Al) and copper $(\mathrm{Cu})$, initial frame at t0, localization without overlay (left) and with strain field overlay of the tensile strain (right) and the failure preparation in the aluminium.

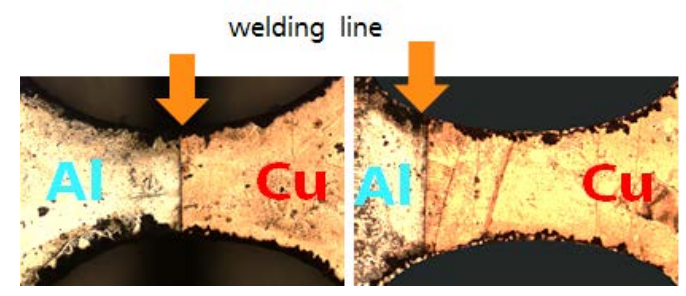

Figure 10: Micro tensile samples with centred welding line (left) and minimum cross section in the copper part (right) for shifting the failure.

\section{CONCLUSIONS AND OUTLOOK}

The micro-testing is a promising tool for local investigations of transient material behaviour in a wide range of strain rates. The application depends on the size of the representative structures in the material. If the sample size includes a quasi-representative structure, the tests can substitute the material characterisation with conventional large samples, especially for the strain rate dependent characterization. Here the main benefit is the wide range of feasible strain rates with only one testing device.

The main field of application will be the local investigation of mechanical performance and the mechanisms influenced by the strain rate. This investigations performed in a sufficient number will allow new correlations of local deformation processes influence by 
the local process induced state of the material. Based on these data combined with innovative data analysis methods and approaches for consideration of uncertainty and scatter the digital material twin could be realized for the mechanical performance analysis.

\section{ACKNOWLEDGEMENTS}

The work presented was partially funded by the Federal Ministry for Economic Affairs and Energy on the basis of a resolution of the German Bundestag within the framework of the IGF projects No. $19532 \mathrm{~N} / 1$ of the research associations FAT (Research Association for Automotive Technology, Germany) and No. 18943 N/1 in cooperation with the Research Associations for Steel Application (FOSTA).

\section{REFERENCES}

[1] ISO 6892-1:2017-02: Metallische Werkstoffe - Zugversuch, Teil 1: Prüfverfahren bei Raumtemperatur (ISO 6892-1:2016); Deutsche Fassung EN ISO 6892-1:2016, 2017.

[2] Böhme, W., FAT-Richtlinie: Dynamische Werkstoffkennwerte für die Crash simulation. Mat. Testing, 50(4), pp 199-205, 2008. DOI: 10.3139/120.100865.

[3] ISO 26203-2:2011: Metallic materials - Tensile testing at high strain rates, Part 2: Servo-hydraulic and other test systems, 2011.

[4] Huberth, F. \& Bimi, P., Dynamic micro testing over five decades of strain rates. 43rd MPA-Seminar, Stuttgart, Germany, 11-12 October, 2017.

[5] Bimi, P., Scalable Dynamic test setup for micro and semi-micro tensile testing. Master's thesis, Fraunhofer IWM, IMTEK University of Freiburg, Freiburg, 2017.

[6] Huberth, F., Bimi, P., Klitschke, S. \& Lienhard, J., Dynamic micro testing over more than five decades of strain rates. ICILSM 2018, Xi'an, China, 7-11 May, 2018.

[7] Sun, D. et al., IGF-Vorhaben 17334N: Entwicklung einer methode zur crashsimulation von langfaserverstärkten thermoplast (LFRT) bauteilen auf basis der faserorientierung aus der formfüllsimulation (IGF-Vorhaben $17334 \mathrm{~N}$ ). Forschungsvereinigung Automobiltechnik e.V. (FAT), FAT-Schriftreihe 284, 2016.

[8] Schulenberg, L. \& Lienhard, J., Strain rate dependent multiaxial characterization of long fiber reinforced plastic. Composite Part B Engineering, 141, S164-S173, 2018. DOI: 10.1016/j.compositesb.2017.12.031F.

[9] Lienhard, J. \& Böhme, W., Characterization of resin transfer molded composite laminates under high rate tension, compression and shear loading. Engineering Fracture Mechanics, 149, S338-S350, 2015.

DOI: $10.1016 /$ j.engfracmech.2015.07.012.

[10] Huberth, F., Lienhard, J. \& Klitschke, S., Rateneffekte und Skaleneffekte bei der Werkstoffprüfung auf der Mikroskala, Tagungsband DVM Tagung Werkstoffprüfung 2018, Günther Moninger (Hrsg.) Deutscher Verband für Materialforschung und prüfung e.V.: Berlin, S261-S266, 2018.

[11] Huberth, F., Klitschke, S., Gall, M., Sommer, S., Schnabel, K. \& Baumgartner, J., Crash and durability of aluminum and mixed steel aluminum joints made by electromagnetic pulse welding. Proceedings ICHSF 2018, Columbus, OH, 2018. OAI ID: eldorado.tu-dortmund.de:2003/369 62 . 